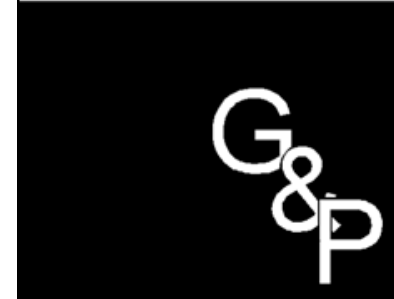

GESTÃO

\&

PRODUÇÃO

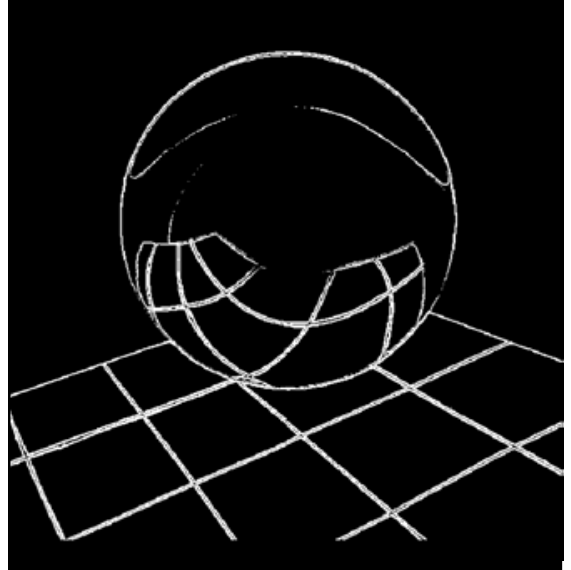

v.6, n.2, p. 97-110, ago. 1999

\section{O PROCESSO PARA OBTENÇÃO DA QUALIDADE DO SUCO DE LARANJA CONCENTRADO CONGELADO BRASILEIRO}

\author{
Ana Claudia Giannini Borges \\ Departamento de Direito e Administração \\ Fundação de Ensino "Eurípedes Soares da Rocha" \\ Marília - SP \\ José Carlos de Toledo \\ Departamento de Engenharia de Produção \\ Universidade Federal de São Carlos - UFSCar \\ São Carlos - SP
}

\title{
Resumo
}

O trabalho investiga o processo de obtenção da qualidade de produto do suco de laranja concentrado congelado. Para tanto, faz-se o levantamento e a análise dos requisitos de qualidade do suco e dos procedimentos adotados pelas empresas para viabilizar o cumprimento das exigências demandadas pelo mercado consumidor e órgãos reguladores. Pela pesquisa de campo foi possível observar que o segmento das empresas processadoras assume uma postura de centralização das informações existentes sobre qualidade na cadeia de produção do suco. Isso é conseqüência da relação direta destas empresas com o mercado externo, destino principal deste produto, e com os órgãos reguladores internacionais e governamentais e demais segmentos componentes desta cadeia. Estes segmentos, sob a coordenação do segmento de processamento, são orientados no sentido de contribuir para a obtenção do suco de laranja concentrado congelado dentro do padrão de qualidade exigido pelo mercado.

Palavras-chave: suco de laranja concentrado congelado; qualidade de produto; relação clientefornecedor; gestão da qualidade.

\section{Introdução}

$\mathrm{N}$ este trabalho tem-se como objetivo identificar os procedimentos e práticas de gestão da qualidade adotados pela indústria de processamento de suco de laranja que proporcionam a obtenção do produto dentro dos padrões de qualidade exigidos pelo mercado consumidor e 
órgãos reguladores - entidades governamentais e internacionais que regulam a qualidade do suco.

$\mathrm{O}$ estudo está restrito aos segmentos e atividades que compõem a agroindústria citrícola no Brasil. O foco do estudo está centrado no segmento de processamento, pois este intermedeia o mercado externo com os demais segmentos componentes da cadeia agroindustrial citrícola. Desta forma, o segmento principal é o de processamento e, num segundo plano, os segmentos de cultivo da fruta, de transporte terrestre da fruta e do suco e o de armazenamento do suco no porto brasileiro.

A pesquisa de campo foi realizada junto às empresas de processamento, em particular nas quatro maiores deste segmento, por representarem $80 \%$ da capacidade instalada de extratoras do Estado de São Paulo: Cutrale, Citrosuco, Coinbra-Frutesp e Cargill.

Para a pesquisa adotou-se um roteiro de investigação e de orientação para discussões e visitas às empresas. A pesquisa foi realizada no período de um ano, de junho de 1996 a junho de 1997. As entrevistas foram direcionadas aos gerentes de qualidade e de produção e aos responsáveis pela matéria-prima (laranja). As questões do roteiro possibilitaram respostas abertas, permitindo maior liberdade de discussão, e algumas questões fechadas a fim de padronizar as respostas. Buscou-se obter informações qualitativas e quantitativas, tornando a investigação mais completa.

\section{A Indústria Nacional e Internacional de Processamento de Suco de Laranja}

A partir da década de 80 a citricultura brasileira foi vista como uma atividade crescente e dinâmica, apresentando um movimento contrário à situação recessiva do país neste período. Essa situação apresentada pela citricultura deve-se em grande parte às geadas sucessivas ocorridas, nesta década, nos pomares norte-americanos, o que proporcionou uma posição de quase monopólio ao Brasil no comércio internacional de suco de laranja. As indústrias processadoras de suco investiram no crescimento da produção da laranja e do suco, a fim de superar o hiato entre demanda e oferta existente, principalmente, no mercado norteamericano.

A produção da fruta e do suco de laranja concentra-se significativamente no Estado de São Paulo, sendo que $80 \%$ da fruta cultivada no estado destina-se ao processamento. Segundo BORGES (1997), a indústria processadora pode ser caracterizada como exportadora considerando os seguintes números: $97 \%$ a $98 \%$ do suco produzido pelas empresas é exportado e o restante, $2 \%$ a $3 \%$, é destinado ao mercado interno. O total de suco exportado pelo Brasil representou $85 \%$ do comércio internacional de suco, até o início da década de 90, segundo SIFFERT FILHO (1992).

Já no início da década de 90 , começa a se observar uma tendência de diminuição do percentual entre a exportação brasileira do suco de laranja concentrado congelado e o seu consumo total. Segundo CITRUS LARANJA (1997), a relação exportação/consumo mundial em 1991/92 foi de 83\%, em 1992/93 de $75 \%$, e no período de 1993 a 1996, cada biênio, apresentou uma relação constante de $66 \%$. Esse dados podem ser observados na Tabela 1.

A indústria citrícola brasileira dispôs na década de 80 de um panorama favorável para o crescimento. Este período caracterizou-se por uma grande euforia, levando a investimentos nos pomares e no processamento do suco no Brasil. No âmbito internacional, o incremento na produção do suco é identificado a partir da década de 90, principalmente com os investimentos norte-americanos nos seus pomares. Nesse período, aumenta a produção norteamericana e surgem outros países produtores que passam a exportar para EUA.

Esse aumento da produção de suco pode ser observado em alguns países, como por exemplo nos EUA que destina sua produção para consumo próprio. Observa-se também essa tendência de crescimento da produção no México, Itália e Espanha no período de 1992 a 
Tabela 1 - Relação entre a exportação brasileira de suco de laranja concentrado congelado e o consumo mundial, 1991 a 1996.

\begin{tabular}{|c|c|c|c|c|c|}
\hline \multirow{2}{*}{ PAÍSES } & \multicolumn{5}{|c|}{ BALANÇO } \\
\hline & 1991/92 & $1992 / 93$ & 1993/94 & $1994 / 95$ & 1995/96 \\
\hline EXPORTAÇÃO TOTAL & 1.314 .908 & 1.333 .604 & 1.301 .234 & 1.304 .865 & 1.347 .151 \\
\hline Brasil & 1.090 .000 & 1.100 .000 & 1.054 .000 & 1.055 .000 & 1.075 .000 \\
\hline Outros & 224.908 & 233.604 & 247.234 & 249.865 & 274.151 \\
\hline CONSUMO & 1.320 .065 & 1.472 .093 & 1.586 .166 & 1.607 .790 & 1.633 .188 \\
\hline $\begin{array}{l}\text { RELAÇÃO } \\
\text { EXPORTAÇÃO/CONSUMO }\end{array}$ & $83 \%$ & $75 \%$ & $66 \%$ & $66 \%$ & $66 \%$ \\
\hline
\end{tabular}

Fonte: elaborado a partir de dados do USDA - Departamento de Agricultura dos EUA, apud CITRUS LARANJA, 1997.

1995 (NEVES, 1996). O Brasil em 1992/1993 era responsável por $51 \%$ do suco de laranja produzido no mundo e em 1994/95 por 47\%. Essa diminuição é decorrente do aumento da produção de suco naqueles países.

Observa-se na exportação de suco de laranja brasileiro para os EUA uma queda a partir de 1985. Esta queda apresenta uma tendência contínua como pode ser observado pelos seguintes números (AMARO \& MAIA, 1996): no período $1980 / 1989$ os EUA importava $47 \%$ do suco brasileiro e no período $1994 / 95$ passou a importar 20,9\%, quantidade necessária para complementar a produção interna do país, que apresenta tendências de crescimento. No período de 1997/98 a exportação de suco brasileiro para os EUA representou $17 \%$ do volume total exportado pelo Brasil. Por outro lado, a exportação de suco brasileiro para Europa apresentou um aumento significativo: no período 1980/89 foi de 38\% e no período de 1994/95 de $61,6 \%$. O Japão começou a importar suco brasileiro no final da década de 80 . No primeiro ano, o volume exportado para o Japão representou $3,6 \%$ das exportações brasileiras e no período 1994/95 chegou a 9,2\%.

À medida que a Indústria Brasileira de Suco de Laranja está orientada para exportação, tendo apresentado uma situação de quase monopólio internacional na década de 80 e tendo como mercado consumidor países desenvolvidos, para os quais a qualidade é uma característica fundamental para qualquer que seja o produto importado, principalmente alimentício, observase que o produto desta agroindústria apresenta um bom padrão de qualidade, além de conseguir manter atualizado esse padrão.

\section{Qualidade de Produto e Gestão da Qualidade}

$\mathrm{Q}_{\mathrm{i}}$ ualidade é um termo utilizado de forma indiscriminada, principalmente nos últimos anos, ocasionando muitas vezes um entendimento equivocado do conceito. Esse problema devese à falta de padronização na utilização do conceito pelas diferentes áreas de conhecimento que o estudam: economia, marketing, engenharia da produção e administração. Isso pode ser melhor identificado em uma empresa, por agregar indivíduos com formação nessas diferentes áreas, o que dificulta o entendimento e integração entre os setores da empresa sobre o tema, muitas vezes prejudicando a obtenção de objetivos comuns na área.

Outro problema é quanto à falta de especificação, que ocorre em muitos casos, ao se utilizar a palavra qualidade. Normalmente utiliza-se esse termo de forma geral, sem se identificar qual entidade está ou não apresentando qualidade, ou seja, muitas vezes falta utilizar um substantivo em conjunto com a palavra qualidade, pois isso 
permite especificar a entidade a que a qualidade se refere. Segundo TOLEDO (1987), deve-se utilizar expressões que precisem o termo qualidade, como: qualidade de produto, qualidade de processo, qualidade de serviços, gestão da qualidade, entre outros.

$\mathrm{O}$ conceito de qualidade de produto, muito difundido nas empresas, é o adotado pela ISO série 9000: "a totalidade de características de uma entidade que lhe confere a capacidade de satisfazer as necessidades explícitas e implícitas" (ABNT, 1994:3). JURAN (1974) conceitua qualidade de produto como sendo "adequação ao uso", significando que a qualidade de um produto está relacionada com o julgamento do usuário, prevalecendo uma análise subjetiva das características do produto. Esta análise ocorre durante o uso do produto e depende da satisfação proporcionada pelo mesmo. Para CROSBY (1984), qualidade é definida como "conformidade com os requisitos". Qualquer que seja o produto, antes de ser usado ou julgado, deve apresentar requisitos previamente definidos, para que a partir destes o consumidor possa julgar se o mesmo apresenta ou não conformidade, ou seja, qualidade. FEINGENBAUM (1961:13) define qualidade de produto como sendo "o composto de características de engenharia e de manufatura, que determinam o grau com que o produto em uso satisfará às expectativas do usuário", o que pode ser considerado uma combinação dos dois conceitos anteriores.

$\mathrm{O}$ conceito de qualidade de produto adotado neste trabalho é "o conjunto de características do produto, avaliadas pelos clientes de acordo com suas exigências, que determina o grau de satisfação que o produto the fornecerá". Para se obter a qualidade de produto a empresa precisa transformar as exigências e requisitos do mercado em características do produto, e adotar as práticas e procedimentos necessários para obter o produto com a qualidade desejada.

As características de qualidade de um produto são definidas a partir das exigências dos clientes, da própria empresa produtora e dos órgãos de regulamentação internacionais e governamentais que atuam na área. Estes são entidades que regulam e exigem um determinado padrão de qualidade do produto, para assim permitir seu consumo e comercialização no mercado internacional ou em países específicos.

Para um produto satisfazer as necessidades e expectativas dos usuários, e ser considerado de qualidade, é necessário que todas as etapas do ciclo de produção estejam integrados, desde a concepção até a distribuição final, abrangendo todas as atividades e agentes envolvidos no ciclo de produção.

O mercado consumidor é um dos agentes condicionantes da definição das características de qualidade do produto, pois a compra de determinado produto está diretamente vinculada à expectativa de satisfação das necessidades dos usuários. Assim, um produto, ao ser projetado, deve relevar as características desejadas pelos usuários.

O produto que proporcionar a satisfação das necessidades dos usuários no momento da compra e durante o período de uso, pode ser considerado de qualidade. Esta satisfação possibilita a lealdade do usuário frente ao produto. $\mathrm{E}$ para que as empresas alcancem esse objetivo é necessário acompanhar a evolução dos hábitos de consumo, que estão em contínua mudança, preservando e possivelmente ampliando a sua parcela de mercado. Isso demonstra a importância de uma relação estreita e constante entre empresa e mercado consumidor e a adoção da gestão da qualidade.

A gestão da qualidade, ou seja, a visão sobre como fazer para obter-se a qualidade pretendida para o produto, evoluiu ao longo deste século, segundo GARVIN (1992), em quatro principais estágios: controle do produto (ou inspeção), controle do processo, sistemas de garantia da qualidade e gestão da qualidade total. A visão de controle do produto limita-se a um enfoque meramente corretivo de inspeção do produto acabado, com o propósito de segregar as unidades de produto não conformes. O controle do processo é um enfoque preventivo centrado no acompanhamento e controle das variáveis do 
processo que podem influir na qualidade final do produto. Os sistemas de garantia da qualidade estão associados a um enfoque relativamente mais amplo e preventivo, que procura, por intermédio de um gerenciamento sistêmico, garantir a qualidade em todas as etapas do ciclo de obtenção do produto. A gestão da qualidade total está associada a um estágio de incorporação da qualidade no âmbito estratégico das organizações, e representa uma visão de como gerenciar globalmente os negócios com uma orientação voltada para a satisfação total do cliente. Tratase de uma visão integrada segundo a qual devese buscar a qualidade total em toda a empresa e em suas relações com o ambiente.

Se para alguns setores a qualidade é uma vantagem competitiva importante, para as indústrias agroalimentares ela é um questão de sobrevivência. Um problema de falta de qualidade, no caso extremo de um produto impróprio ao consumo humano, pode afetar de maneira importante a imagem de uma marca consolidada no mercado, comprometendo-a definitivamente. Dificilmente um consumidor que viu sua saúde prejudicada pela ingestão de um produto deteriorado ou contaminado, arriscaria novamente, se fosse possível evitar, a compra de tal produto.

Segurança e qualidade são duas dimensões inseparáveis em todas as fases da cadeia agroalimentar e requerem mais do que regulamentações e ações de inspeção governamental. Segurança e qualidade dependem da cultura e do conhecimento de todos, ao longo da cadeia, no sentido da prevenção e da prática da melhoria contínua, tendo em vista o consumidor final. É fundamental, nas cadeias, os esforços coordenados e voluntários de identificação das causas dos problemas e a tomada de ações corretivas e preventivas pertinentes. Ou seja, a gestão da qualidade em uma cadeia agroalimentar depende da participação consciente e voluntária de todos os envolvidos para que os ganhos sejam obtidos e usufruídos por todos. Isso depende da conscientização e da capacitação para aplicação de boas práticas de manufatura e de higiene em toda a cadeia, segundo TOLEDO (1997).
Esta constatação evidencia a necessidade de coordenação das ações, que influem na qualidade final, ao longo de toda a cadeia e também a conscientização de que a gestão da qualidade de uma unidade de produção deve transcender os limites da mesma.

\section{Processo de Obtenção da Qualidade de Produto do Suco de Laranja Concentrado Congelado}

\subsection{Exigências do Mercado Consumidor}

$\mathrm{O}$ mercado consumidor do suco de laranja concentrado congelado brasileiro é composto principalmente pela Europa, Japão e EUA, que correspondem a praticamente $91,7 \%$ do suco exportado pelo Brasil no período de 1994/95.

O Japão e a Europa podem ser considerados como os mercados consumidores mais exigentes em relação à qualidade do produto. A Europa demanda padrões de qualidade de vários órgãos reguladores, inclusive do USDA - United States Department of Agriculture. O Japão é considerado um país muito exigente em relação à qualidade, e não adota os padrões estabelecidos e utilizados internacionalmente. Este país formula padrões próprios que são considerados mais restritos e específicos, dificultando o cumprimento das exigências. As empresas de processamento alegam que esses dois mercados consumidores apresentam uma maior gama de exigências em relação ao suco, por não apresentarem conhecimento e experiência suficiente, como o Brasil e os EUA, no processamento do suco. Com isso, os EUA, frente a esses dois mercados, não podem ser caracterizado como um país com elevado grau de exigência.

Em conjunto aos padrões exigidos pelo mercado consumidor, as empresas processadoras precisam relevar as exigências demandadas pelos órgãos reguladores internacionais (Codex Alimentarius e AIJN - Association International Juice and Nectare Fruit) e governamentais (JAS - Japanese Agricultural Standard e USDA). Esses órgãos regulam a qualidade do suco de 
laranja, permitindo ou não a importação do suco brasileiro pelos países consumidores.

O consumidor final do suco de laranja brasileiro não tem contato direto com o segmento de processamento do suco no Brasil. Esta relação é intermediada pelas empresas de diluição e envasilhamento, no exterior, as quais acrescem suas exigências às dos consumidores e repassam-nas às empresas processadoras, que acrescentam as exigências dos órgãos reguladores. As empresas de diluição e envasilhamento compram o suco das empresas processadoras e, após manipular, revendem ao consumidor final ou aos distribuidores.

As exigências do consumidor final são identificadas e traduzidas pelas empresas de diluição e envasilhamento. Após, acrescentam suas exigências e repassam-nas para as empresas de processamento. Esta etapa de tradução, realizada pelas empresas de diluição e envasilhamento e, posteriormente, pelas empresas de processamento, deve ser realizada com precisão, para que o suco produzido atenda às exigências do consumidor. Vale salientar que, como a empresa processadora não está em contato direto com o consumidor final, precisa confiar na capacidade das empresas de diluição e envasilhamento em acrescentar as suas exigências aquelas que são efetivamente provenientes das expectativas do consumidor final.

As características essenciais que compõem a qualidade do suco de laranja e que estão relacionadas com as exigências demandadas pelo mercado consumidor, pelos órgãos reguladores e pelas empresas processadoras, são dos seguintes tipos:

- Físico-químicas: rátio (índice de acidez), Brix (porcentagem de sólido existente em um determinado produto líquido), vitaminas, ácidos, compostos nitrogenados, porcentagem da polpa, óleo.

- Organolépticas: sabores, cor, aroma.

- Microbiológicas: limitação da quantidade de microorganismos contidos no suco.

- Práticas de processo: autenticidade do produto, controle de pesticidas na fruta, controle de metais pesados.
As empresas analisam as exigências dos seus clientes para classificarem essas características em função de sua maior ou menor relevância para obtenção do produto com a qualidade solicitada, como pode ser verificado na Tabela 2.

\subsection{Cadeia Agroindustrial Citrícola: Relação Cliente-Fornecedor}

Neste item apresentam-se os principais segmentos que compõem a cadeia agroindustrial citrícola e o relacionamento entre eles. Um segmento pode ser classificado ora como fornecedor, ora como cliente, dependendo da posição relativa em que está sendo analisado na cadeia. $\mathrm{O}$ relacionamento entre esses segmentos deve ocorrer de forma clara e objetiva, a fim de obter um produto ou um serviço que cumpra as exigências de seu cliente, seja este um segmento da cadeia ou um consumidor final. Na Figura 1, observa-se os segmentos componentes da cadeia agroindustrial citrícola no Brasil, o mercado externo e os órgãos reguladores e como se dá a relação cliente-fornecedor entre eles.

As exigências demandadas pelo consumidor final são detectadas e traduzidas pelas empresas de diluição e envasilhamento do suco para uma terminologia utilizada pelas empresas de processamento, possibilitando uma melhor compreensão dos requisitos de qualidade exigidos e, com isso, a satisfação do mercado consumidor e das restrições dos órgãos reguladores.

O segmento de processamento pode ser caracterizado como fornecedor do mercado externo, e por isso precisa satisfazer as necessidades desse mercado e cumprir as exigências dos órgãos reguladores. A fim de cumprir os requisitos de qualidade, as empresas adotam práticas e procedimentos internos à sua "planta" fabril. Mas, as medidas não se restringem a isso, pois as empresas processadoras também exigem certos requisitos dos seus fornecedores de bens e serviços. Os fornecedores do segmento de processamento são os demais segmentos (produção citrícola, transporte da fruta, embalagens, 
Tabela 2 - Classificação pelas empresas das características do suco de laranja concentrado congelado demandadas pelos clientes e órgãos reguladores.

\begin{tabular}{|c|c|c|c|}
\hline \multirow{2}{*}{$\begin{array}{l}\text { Características do suco de } \\
\text { laranja concentrado congelado } \\
\text { demandadas pelos clientes }\end{array}$} & \multicolumn{3}{|c|}{ Classificação quanto ao grau de importância para as empresas } \\
\hline & Tipos & $\begin{array}{c}\text { Maior } \\
\text { importância }\end{array}$ & $\begin{array}{c}\text { Menor } \\
\text { importância }\end{array}$ \\
\hline Físico-químicas & $\begin{array}{l}\text { Rátio } \\
\text { Brix } \\
\text { Vitaminas } \\
\text { Ácidos } \\
\text { Compostos nitrogenados } \\
\text { Porcentagem da polpa } \\
\text { Óleo } \\
\end{array}$ & $\begin{array}{l}\text { A, B, C e D } \\
B, C \text { e D } \\
\text { C } \\
\text { A, B e C } \\
\text { C } \\
\text { A, B, C e D } \\
B, C \text { e D }\end{array}$ & $\begin{array}{l}\text { A } \\
\text { A, B e D } \\
\text { D } \\
\text { A, B e D } \\
\text { A }\end{array}$ \\
\hline Organolépticas & $\begin{array}{l}\text { Sabores } \\
\text { Cor } \\
\text { Aroma } \\
\end{array}$ & $\begin{array}{l}\text { A, B, C e D } \\
\text { A, B, C e D } \\
\text { A e C }\end{array}$ & B e D \\
\hline Microbiológicas & Microorganismos & $\mathrm{A}, \mathrm{B}, \mathrm{C}$ e D & \\
\hline Práticas de processo & $\begin{array}{l}\text { Autenticidade do produto } \\
\text { Controle de pesticidas } \\
\text { Controle de metais pesados }\end{array}$ & $\begin{array}{l}\text { A, B, C e D } \\
\text { A, B, C e D } \\
\text { A, C e D }\end{array}$ & B \\
\hline
\end{tabular}

Obs.: as letras A, B, C e D correspondem às empresas entrevistadas.

transporte terrestre e armazenamento do suco no porto) que compõem esta cadeia.

O segmento de produção citrícola recebe as exigências quanto à qualidade da fruta. Segundo STENGER (1990), e entrevistas com especialistas da área, a qualidade do suco de laranja tem como principal determinante a qualidade da fruta. A qualidade intrínseca da fruta tende a diminuir a partir da colheita. Esta tendência declinante da qualidade do suco da fruta é contínua, até a distribuição do suco pronto e o seu consumo. Portanto, é fundamental que a qualidade da fruta não ultrapasse o limite mínimo aceitável, para não prejudicar a qualidade final do suco.

As demais atividades, inclusive o processamento, têm como função manter a qualidade do suco, a fim de proporcionar ao consumidor final um produto o mais próximo possível do desejado. Portanto, as atividades de colheita, transporte da fruta, processamento, transporte e armazenamento do suco, devem ser realizadas seguindo procedimentos necessários para que o produto final tenha a qualidade desejada. Se os demais segmentos não adotarem os cuidados adequados, o suco poderá chegar ao consumidor final com a qualidade abaixo do limite mínimo aceitável.

Os requisitos a serem cumpridos pelo segmento de produção citrícola são quanto às características fitossanitárias, à cor e tamanho da fruta e à maturação, uma vez que a fruta sofre variações de acordo com o clima e a safra.

As empresas de processamento preocupam-se com os aspectos sanitários a fim de evitar frutas podres, manchadas, que estão no chão há algum tempo, com doença, com picadas de insetos e contaminadas com pesticidas. Esta postura de vigilância visa prevenir o risco de contaminação do suco, que ocasionaria rejeição no mercado consumidor.

O segmento de transporte entrega as frutas às empresas de processamento. Com a mudança do contrato em 1995/1996, entre os segmentos de processamento e de produção citrícola, o transporte da fruta passou a ser responsabilidade 


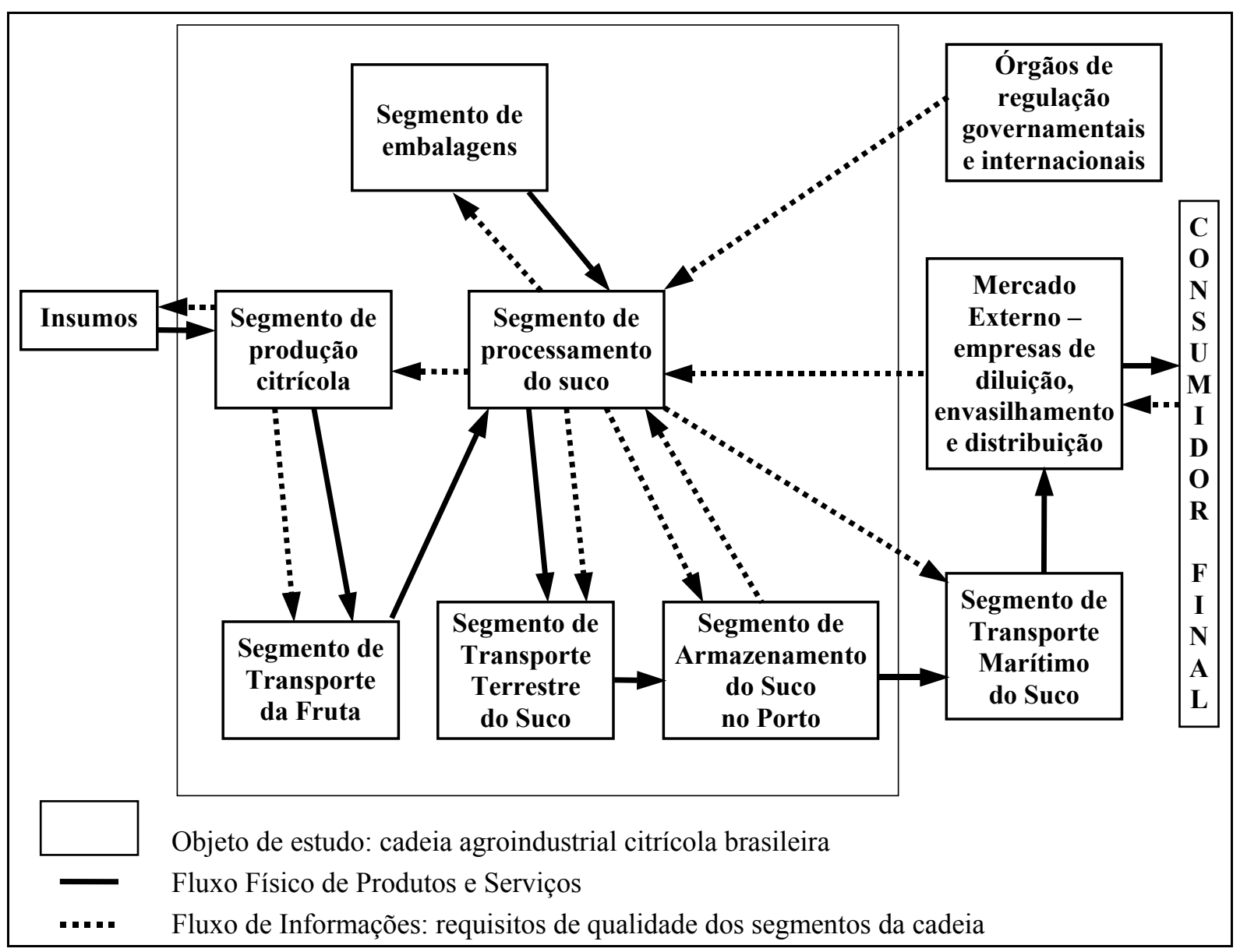

Figura 1 - Sistema de produção do suco de laranja concentrado congelado Fonte: BORGES (1997).

dos produtores da fruta e não mais do segmento de processamento.

O segmento de embalagens é representado por empresas produtoras de tambores, sacos de plástico e tanques, que devem cumprir as especificações exigidas pelas processadoras.

O segmento de transporte terrestre do suco até o porto, para algumas empresas de processamento, é uma atividade realizada por ela mesma e, para outras, é terceirizada integral ou parcialmente. Independentemente de quem realiza esta atividade, o serviço de transporte do suco de laranja, da empresa de processamento até o porto, é caracterizado como uma atividade fornecedora e a sua cliente é a empresa de processamento. Para cumprir as exigências das empresas processadoras é necessário que alguns procedimentos sejam cumpridos, como: sanitização e limpeza periódica dos tanques; controle de temperatura e controle do tempo de transporte.

O segmento de armazenamento do suco no porto, segue as mesmas condições que o segmento de transporte terrestre do suco quanto à terceirização. Exceto quanto ao fato das exigências serem demandadas pelas empresas de processamento e o suco ser deslocado pelo segmento de transporte até o segmento de armazenamento. Para realizar a atividade de armazenamento com qualidade, é necessário que o suco recebido da atividade de transporte esteja dentro do padrão estipulado pela empresa processadora. 
Todas essas exigências demandadas aos segmentos de embalagens, transporte e armazenamento do suco têm como finalidade manter a qualidade, obtida no processamento. Deve-se ressaltar, entretanto, que o suco terá qualidade, em primeira instância, se a laranja selecionada apresentar qualidade, ou seja, se cumprir as exigências do segmento processador.

\subsection{Procedimentos Adotados pelas Empresas Processadoras}

As empresas entrevistadas destacaram a importância da comunicação clara e objetiva entre seus departamentos e setores, pois só assim é possível assegurar um atendimento adequado das exigências do mercado consumidor.

O departamento comercial deve estar em contato com os clientes da empresa e com os demais departamentos. O departamento de suprimentos analisa as exigências dos clientes, averiguando se há condições de satisfazer a demanda com a safra de laranja apresentada no respectivo ano. $\mathrm{O}$ departamento industrial verifica se as instalações físicas da fábrica são adequadas para o cumprimento das exigências. E, por fim, o departamento de garantia da qualidade define os controles necessários durante o processamento e no recebimento da matéria-prima, para se obter o suco com os requisitos demandados.

As exigências específicas demandadas pelos clientes e órgãos reguladores às empresas processadoras são consideradas, por estas, como relevantes, desde que: a capacidade de produção instalada seja adequada para o atendimento dessas exigências; o cumprimento do contrato firmado com demais clientes não seja comprometido; e as mudanças climáticas não inviabilizem a obtenção do suco desejado. A exigência de um cliente deve ser atendida desde que não comprometa a produção do suco para os demais clientes, pois para a empresa é preferível não cumprir as exigências de um cliente, em específico, do que comprometer a obtenção do suco exigido pelos demais clientes. As exigên- cias de um cliente podem se referir a um novo requisito de qualidade do produto (por exemplo um novo sabor) ou a um valor (especificação) de um requisito de qualidade diferente do tradicionalmente exigido (por exemplo um grau de brix mais elevado).

O clima e as características da fruta, em determinadas safras, são uma das preocupações das empresas de processamento, uma vez que podem inviabilizar o padrão de qualidade desejado. Para sanar tais dificuldades em relação à qualidade da fruta, adotam-se algumas práticas no processamento, tais como: blendagem de suco (brix e rátio), combinação de variedades de frutas, adição de óleos essenciais, aromatização natural e controle da época de colheita, solicitando-se ao fornecedor frutas em diferentes épocas de colheita, atrasando ou adiantando esta atividade. A classificação dessas práticas, segundo as empresas entrevistadas, pode ser vista na Tabela 3.

As empresas A, B e D classificaram o controle da época da colheita como a principal prática que viabiliza a obtenção do suco de laranja com a qualidade exigida pelos clientes, seguido pela blendagem de sucos e a combinação de variedades de frutas.

O controle da época da colheita é uma prática que permite à empresa determinar qual será a acidez e a quantidade de sacarose do suco, após processar a fruta. Quando há atraso na colheita da fruta observa-se uma diminuição da acidez, um aumento da sacarose e uma diminuição da quantidade de água. A blendagem é uma prática utilizada pelas empresas que visa misturar sucos de diferentes rátio e brix, para obter o produto com as características demandadas pelo cliente. A combinação de variedades de frutas é uma prática utilizada apenas entre as diversas variedades de laranja e não com frutas diferentes. Segundo VIÉGAS (1991), algumas variedades como Pêra, Valência e Natal apresentam maior rendimento e suco de melhor qualidade; a Hamilin permite que a fábrica produza no início da safra; a Tangerina-Cravo e Mexerica são usadas para a obtenção da coloração do suco. 
Tabela 3 - Práticas utilizadas pelas empresas para obter o suco com as características demandadas.

\begin{tabular}{|l|c|c|c|}
\hline \multirow{2}{*}{ Tipos } & \multicolumn{2}{c|}{ Classificação segundo o grau de importância } \\
\cline { 2 - 4 } & Empresa A & Empresa B & Empresa D \\
\hline Blendagem de sucos & $3^{\circ}$ & $2^{\circ}$ & $2^{\circ}$ \\
\hline Combinação de variedades de frutas & $2^{\circ}$ & ------- & $2^{\circ}$ \\
\hline Adição de óleos essenciais & $4^{\circ}$ & $3^{\circ}$ & $3^{\circ}$ \\
\hline Aromatização natural & $4^{\circ}$ & $3^{\circ}$ & $3^{\circ}$ \\
\hline $\begin{array}{l}\text { Controle da época da colheita (antes e depois } \\
\text { da época) }\end{array}$ & $1^{\circ}$ & $1^{\circ}$ & $1^{\circ}$ \\
\hline
\end{tabular}

${ }^{1}$ A empresa $C$ não respondeu a esta pergunta.

Obs.: os números 1, 2, 3, 4 e 5 são utilizados para classificar em grau de importância dos cinco tipos de práticas destacadas na tabela. As empresas, ao classificarem as práticas em grau de importância, ora utilizam 3, ora 4 números, pois há casos em que duas práticas têm o mesmo grau de importância.

A análise laboratorial intensa é outro dos procedimentos adotados pelas empresas de processamento, internamente e junto ao fornecedor, para garantir o padrão de qualidade da fruta e do suco. As análises são realizadas na fruta durante todas as fases de crescimento, a fim de acompanhar e certificar-se do grau de qualidade da mesma e, portanto, do suco. As análises laboratoriais não se restringem a essa atividade, mas também ocorrem nas demais atividades externas ao processamento, tais como nas atividades de transporte e armazenamento do suco, a fim de assegurar que possíveis variações das características ocorram dentro dos limites permitidos.

As empresas processadoras investem em aspectos estruturais, gerenciais e organizacionais, que viabilizam a obtenção do suco de laranja dentro do padrão de qualidade exigido pelo mercado consumidor. Para se ter um panorama da situação das empresas entrevistadas, quanto aos recursos e meios utilizados para obter a qualidade demandada pelos clientes, a Tabela 4 apresenta a posição de cada empresa quanto a esses meios.

Um desses aspectos está relacionado aos fornecedores, especificamente ao desenvolvimento e capacitação, onde as empresas incentivam esta relação de forma e em graus diferentes. A atenção ao fornecedor aumentou após a mudança do contrato de compra da laranja, ocorrido em 1995/96, quando as empresas processadoras desvincularam-se da produção citrícola. Esta mudança intensificou os cuidados com a qualidade da fruta e com o controle de pesticidas. Essa mudança do contrato, mais a adoção da ISO 9000, estimulou um relacionamento mais estreito da empresa processadora com os fornecedores de laranja, investindo-se na capacitação e desenvolvimento desses, objetivando a obtenção da fruta e do suco com qualidade.

A capacitação dos funcionários é outro aspecto fundamental apontado pelas empresas, como viabilizador para obter o suco dentro dos padrões exigidos pelo mercado consumidor. Esta capacitação é obtida com o treinamento, buscando um quadro de pessoal mais qualificado e homogêneo.

Todas as empresas também identificam a conscientização dos funcionários como um aspecto fundamental, pois permite um conhecimento global do processo, da importância de seu trabalho para a empresa e para a obtenção do produto com qualidade. Isso é viabilizado com programas de treinamento.

As empresas destacam a relevância da comunicação com os clientes. Para manter sua parcela de mercado é necessário identificar e atender as exigências deste, por meio de uma comunicação direta com os clientes. 
Tabela 4 - Recursos e meios utilizados pelas empresas que auxiliam na obtenção da qualidade do produto.

\begin{tabular}{|c|c|c|c|c|c|}
\hline \multirow[b]{2}{*}{ Áreas/Atividades } & \multirow[b]{2}{*}{ Tipos } & \multicolumn{4}{|c|}{ Classificação quanto a implementação } \\
\hline & & $\begin{array}{l}\text { Não está nos } \\
\text { planos }\end{array}$ & $\begin{array}{l}\text { Está em } \\
\text { estudos }\end{array}$ & $\begin{array}{l}\text { Está em } \\
\text { implemen- } \\
\text { tação }\end{array}$ & $\begin{array}{c}\text { Já está } \\
\text { implemen- } \\
\text { tado }\end{array}$ \\
\hline Fornecedores & $\begin{array}{l}\text { Desenvolvimento e capacitação de } \\
\text { fornecedores. }\end{array}$ & & B e D & & $\mathrm{A}$ e $\mathrm{C}$ \\
\hline Recursos Humanos & $\begin{array}{l}\text { Capacitação de RH. } \\
\text { Conscientização dos funcionários. }\end{array}$ & & & B & $\begin{array}{c}\text { A, C e D } \\
\text { A, B, C e D }\end{array}$ \\
\hline $\begin{array}{l}\text { Identificação das } \\
\text { necessidades dos } \\
\text { clientes } \\
\end{array}$ & Comunicação com os Clientes. & & & & $\mathrm{A}, \mathrm{B}, \mathrm{C}$ e $\mathrm{D}$ \\
\hline $\begin{array}{l}\text { Sistema de Gestão } \\
\text { Ambiental }\end{array}$ & ISO 14000. & $\mathrm{D}$ & $\mathrm{A}, \mathrm{B}$ e $\mathrm{C}$ & & \\
\hline Gestão da Qualidade & $\begin{array}{l}\text { Programa de Qualidade Total. } \\
\text { Sistema da Qualidade (ISO 9000). }\end{array}$ & & $\mathrm{B}$ & $\begin{array}{l}\mathrm{A} \\
\mathrm{A}\end{array}$ & $\begin{array}{c}\text { C e D } \\
\text { B, C e D }\end{array}$ \\
\hline $\begin{array}{c}\text { Inovação } \\
\mathrm{e} \\
\text { Tecnologia } \\
\end{array}$ & $\begin{array}{l}\text { Laboratório de desenvolvimento. } \\
\text { Acesso a novas tecnologias. } \\
\text { Automação do processo. }\end{array}$ & & & & $\begin{array}{l}\text { A, B, C e D } \\
\text { A, B, C e D } \\
\text { A, B, C e D }\end{array}$ \\
\hline Processo & Controle de processo. & & & & $\mathrm{A}, \mathrm{B}, \mathrm{C}$ e $\mathrm{D}$ \\
\hline Distribuição & $\begin{array}{l}\text { Gerenciamento da Distribuição dos } \\
\text { produtos. }\end{array}$ & & & & $\mathrm{A}, \mathrm{B}, \mathrm{C}$ e $\mathrm{D}$ \\
\hline
\end{tabular}

Obs.: empresas A, B, C e D.

A gestão ambiental é considerada como um tema de relevância para as empresas processadoras. A ISO 14000 não foi adotada pelas empresas, mas já está em estudos ou em implementação. As empresas já adotam práticas que auxiliam na gestão ambiental, como a diminuição da emissão de dejetos nas águas próximas à empresa.

A gestão da qualidade é uma necessidade para as empresas obterem produtos dentro do padrão de qualidade exigido pelos clientes, por isso adota-se programas da qualidade e outros programas integrados à qualidade. Alguns destes programas e conceitos utilizados são: BPM boas práticas de manufatura; APPCC - Análise de Perigos e Pontos Críticos de Controle; e programas voltados ao controle do processo. Além disso adota-se algumas normas internacionais do setor de alimentos e de food safety. A ISO 9000 também pode ser considerada fundamental para as empresas, sendo que a certificação para algumas empresas está concluída e para outras a comercialização e a qualidade de seus produtos não está vinculada a esta certificação, pois a aceitação do produto está relacionada às visitas e auditorias do próprio cliente nas instalações fabris.

A inovação de produtos é uma prática adotada pelas empresas, com o auxílio dos laboratórios de desenvolvimento que viabilizam a obtenção de um suco cada vez mais próximo do demandado pelos clientes. Os hábitos de consumo modificam-se continuamente e em conjunto as exigências do mercado, intensificando a necessidade de aperfeiçoamento constante do produto. Isso é viabilizado com a busca de novas tecnologias e a automação de determinadas etapas do processo, principalmente as etapas consideradas fundamentais, tal como a de concentração.

A distribuição é considerada uma atividade fundamental para as empresas, pois possibilita a manutenção da qualidade de produto obtida no final do processamento. Nesse sentido, as 
empresas buscam melhorias no sistema logístico, como as ocorridas no transporte e no armazenamento do suco, com o surgimento do tank farm, no início dos anos 80 .

Com essas práticas e procedimentos busca-se a obtenção do melhoramento constante da qualidade de produto do suco de laranja, permitindo a satisfação das exigências dos consumidores ainda que essas estejam em constante evolução.

\section{Considerações Finais}

A produção do suco de laranja concentrado congelado brasileiro destina-se quase que totalmente à exportação. Os países e regiões importadores desse produto são considerados de "primeiro mundo", onde a qualidade é componente obrigatório em qualquer produto, principalmente tratando-se de produtos alimentícios, que precisam apresentar elevados níveis de qualidade e segurança.

O Brasil apresenta uma posição privilegiada no mercado internacional de suco. Um fator fundamental para a obtenção desta posição é quanto à capacidade de centralização e coordenação das informações referentes aos requisitos de qualidade da cadeia agroindustrial citrícola no segmento de processamento. Este segmento atua como articulador da cadeia com o mercado por representar o centro de gravidade desta cadeia, ou seja, é o foco de articulação entre o mercado externo - empresas de diluição e envasilhamento - e órgãos reguladores de um lado, com os segmentos fornecedores de matéria-prima, de serviços e de embalagens de outro.

As informações, em um primeiro momento, convergem para as empresas do segmento processador e depois para os seus fornecedores de matéria-prima, embalagem e serviços. $\mathrm{O}$ fluxo de requisitos direciona-se para a empresa processadora a qual, após acrescentar a essas informações os seus próprios requisitos, encaminha-os aos seus fornecedores.

Essa centralização significa que o segmento de processamento, ao receber os requisitos de qualidade demandados pelo mercado consumidor e órgãos reguladores, realiza um conjunto de práticas e procedimentos que viabilizarão o cumprimento destas exigências, pelo intermédio de medidas internas e externas à empresa.

As medidas internas são um conjunto de práticas de processamento organizacionais e de gerenciamento que estão em implantação ou implantadas, facilitando $o$ atendimento dos clientes da melhor forma possível e viabilizando a obtenção do suco com a qualidade desejada.

As medidas externas estão relacionadas com as exigências demandadas pelo segmento de processamento aos seus fornecedores. Estes podem dificultar a obtenção do produto final com a qualidade desejada pelos consumidores, por não realizarem suas atividades com os cuidados adequados. Como a qualidade do suco está diretamente vinculada à qualidade da fruta, e as demais atividades da cadeia de produção agroindustrial citrícola têm como principal função manter a qualidade do suco a mais próxima da qualidade da fruta, essas atividades devem cumprir todas as exigências do segmento de processamento.

As empresas de processamento fazem suas exigências aos fornecedores, mas não exercem controle sobre a realização das atividades, internas a estes, de obtenção dos produtos e serviços demandados. Essa falta de controle pode ocasionar alterações em algumas características do suco, que poderão ser detectadas no ato de diluição e envase do suco ou durante o consumo.

A obtenção do suco de laranja com a qualidade desejada está vinculada à qualidade da fruta, que pode ser afetada por qualquer mudança climática, problemas fitossanitários ou nos procedimentos de cultivo, colheita e demais atividades de manuseio da fruta de forma não adequada. Isso pode alterar as características do suco exigidas pelo mercado consumidor e órgãos reguladores.

A questão fitossanitária é fundamental para a obtenção da qualidade do suco e, também, pode ser considerada como uma das principais 
limitações para tal. O cancro cítrico é um exemplo da falta de qualidade fitossanitária nos pomares, e isso prejudica a obtenção da qualidade das frutas e portanto do suco. Um dos principais problemas é a dificuldade de erradicar o cancro, podendo comprometer e, até mesmo, destruir os pomares.

As instalações físicas da fábrica também podem ser consideradas limitações para a obtenção do suco dentro dos padrões de qualidade exigidos, pois as instalações podem ter restrições para atender uma determinada demanda e a possibilidade em cumprir tal exigência pode comprometer o suco dos demais clientes, se houver a necessidade de direcionar toda a produção para o cumprimento de tais exigências.

A empresa de processamento, visando superar tais limitações, incentiva a comunicação e integração com os seus clientes e fornecedores e entre os seus departamentos internos. Além disso, adota-se a prática de coleta e análise de amostras de suco durante o processamento, transporte e armazenamento, rastreando as atividades internas e externas à empresa e, com isso, controlando a qualidade do suco caso este sofra alguma alteração em suas características, devido a execução de uma atividade de forma inadequada.

\section{Referências Bibliográficas}

ABNT - Associação Brasileira de Normas Técnicas: "Gestão da qualidade e garantia da qualidade - terminologia." NBR ISO 8402, dez/1994, p.1-9.

AMARO, A.A. \& MAIA, M.L.: "Os novos caminhos da citricultura." Agroanalysis, jun/1996., p.25-27.

BORGES, A.C.G.: O Processo de Obtenção da Qualidade de Produto do Suco de Laranja Concentrado Congelado. São Carlos, 160p. Dissertação de Mestrado em Engenharia de Produção - UFSCar, 1997.

CITRUS LARANJA: Agrianual, São Paulo, p.199215, 1997. (FNP Consultoria \& Comércio)
Para se alcançar a qualidade do produto final, observa-se a importância de: identificar, interpretar e desdobrar as exigências dos clientes; existir uma comunicação direta e clara na relação cliente-fornecedor entre os diversos segmentos da cadeia de produção e entre os departamentos das empresas; adotar e exigir as práticas e os procedimentos de colheita, processamento, transporte e armazenamento que assegurem um controle de todo o processo.

As práticas e procedimentos identificados se mostram, hoje, suficientes para a obtenção do produto suco de laranja dentro dos padrões exigidos pelo mercado consumidor e órgãos reguladores, mesmo com a existência de limitações intrínsecas (clima, problemas de ordem fitossanitária e capacidade instalada de processamento) a essa cadeia. Isso pode ser comprovado pelo alto grau de aceitação do suco brasileiro nos mercados mais exigentes, como na Europa e Japão. Entretanto, questões ainda presentes tais como as de ordem fitossanitária e a necessidade de assegurar a qualidade da laranja fornecida, têm levado à busca de novas ações no setor, coordenadas pelo segmento de processamento, no sentido da difusão de sistemas de garantia da qualidade junto ao segmento da produção citrícola, para manutenção e melhoria dos padrões de qualidade do suco e de rendimento do processo.
CROSBY, P.B.: Qualidade é Investimento. Rio de Janeiro, José Olympio, 1984.

FEIGENBAUM, A.V.: Total quality control: engineering and management. New York, McGRAW-HILL, 1961.

GARVIN, D.: Gerenciando a qualidade: a visão estratégica e competitiva. Rio de Janeiro, Qualitymark, 1992.

JURAN, J.M.: "Basic concepts." In: JURAN, J.M.; GRYNA JR., F.M.; BINGHAM JR., R.S. Quality control handbook. New York, McGRAW-HILL, $3^{\mathrm{a}}$ ed., p.2.1-2.24, 1974. 
NEVES, E.M. et ali: "Análises comparativas de custos de laranja para a indústria: São Paulo (Brasil) e Florida (EUA)." Laranja, v.14, n.1, p.31-44, 1993.

SIFFERT FILHO, N.F.: "Citricultura e indústria: organização e mercado." Rascunho. Rio Claro, SP, Unesp - IGCE, n.22, 62 p, 1992.

STENGER, E.: "Trinta Anos de Desenvolvimento em Processamento de Citrus - História, Estado de Arte e Visão Geral.” Laranja, v.11, n.2, p.463502, 1990.
TOLEDO, J.C.: Qualidade industrial: conceitos, sistemas e estratégias. São Paulo, Atlas, 1987.

: Gestão da qualidade na Agroindustria, cap.8. In: BATALHA, M.O. et ali. Gestão Agroindustrial. São Paulo, Atlas, p.437-487, 1997.

VIÉGAS, F.C.P.: “A industrialização dos produtos cítricos.” In: RODRIGUES, O. et ali. Citricultura Brasileira. Fundação Cargill, v.2, p.898-922, 1991.

\title{
PROCEDURES TO OBTAIN QUALITY FROZEN CONCENTRATED ORANGE JUICE
}

\begin{abstract}
This study investigates the process of obtaining world class quality in frozen concentrated orange juice. A survey and analysis of juice quality requirements and procedures adopted by the processing companies were performed. From the field survey it was observed that the segment of processing companies assumes a centralizing attitude concerning the information presented in the production system of frozen concentrated orange juice. This is a consequence of direct contact with the international market, the main destinations of the product (USA \& Europe), and the regulatory bodies and other segments belonging to the system. These segments (juice processing, packing, citric production, fruit transport, juice ground transport and stocking transport), under the coordination of the processing companies, seek to accomplish their activities in the best possible way to obtain world class quality frozen concentrated orange juice.
\end{abstract}

Key words: frozen concentrated orange juice; product quality; client-provider related; quality management. 